\title{
THE FUNCTIONS OF HUMOROUS DISCOURSE IN MIND YOUR LANGUAGE
}

\author{
M. Masqotul Imam Romadlani' ${ }^{\text {and I Dewa Putu Wijana }}{ }^{2}$
}

\author{
1imam.romadlani@gmail.com, ${ }^{2}$ idp_wijana@yahoo.com \\ Gadjah Mada University \\ Sleman, Yogyakarta, Indonesia
}

\begin{abstract}
The primary purpose of this study is to reveal the function of humorous discourse identified in the Mind Your Language situation comedy series. The researcher adopted a descriptive qualitative approach to complete this humor research. The data were obtained from the script of that sitcom. The function of humorous discourse found in that sitcom was then classified based on Hay's framework, which divides the function of humor into three main functions: the function of solidarity, the function of power, and the function of psychology. The findings demonstrate that teasing and satire humor in Mind Your Language sitcom are utilized to express solidarity. Meanwhile, humorous discourses that trigger conflict, harm, threaten others or show disagreement are created to express the function of power. Furthermore, humorous discourse to gain an advantage, protect oneself, entertain, or boast is used to express the function of psychology. The context of the conversation given is highly significant in identifying the function of humor. The same humorous discourse provided in different contexts potentially implicates different functions of humor which indicates that determining the function of humor is heavily grounded by the context.
\end{abstract}

Keywords: humorous discourse; Mind Your Language; the function of humor.

\section{INTRODUCTION}

Humor, theoretically, is divided into three fundamental theories, superiority theory, relief or release theory, and incongruity theory. Superiority theory relates to the process of creating humor by pointing out the shortcomings or misfortunes experienced by others. From that superiority perspective, humor is expressed in laughing at or pointing out the weakness or bad luck of a person or a particular group. There is a feeling of superiority over someone or a more inferior group. The second theory of humor, relief theory, emphasizes creating humor as a psychological expression after releasing a drastic sense of tension. When people are drastically relieved of their tension or panic feeling, they tend to express it by laughing or smiling as a humor indication. According to Mulphurs (2010), laughter and humor are closely intertwined concepts with a distinct function. Looking at laughter and smiles as the leading indicators of humor, grins, or even sudden exhalations also indicate such experience of humor as the additional indicators proposed by Meyer (2000).

Besides the theories above, incongruity theory is closely related to linguistic aspects in creating humor. Speaker, intentionally or unintentionally, distorts the rules or principles of language used to elicit humor. It triggers an opposition between what is expected and what happened. Goldman (2013) defines humor as a pleasant state of a discrepancy between what is expected to happen and what is experienced. That concept of incongruences is characterized by contradiction, contrast, and difference (Marmysz, 2003). Consequently, Kuipers (2009) considers that incongruity is a fundamental ingredient of humor production characterized by the apposition of mismatched elements.

Ross (2005) asserts that humor is the quality or potential of someone or something 
to be funny, either in audio, visual, or audiovisual. Hurley, Dennett, and Adams (2011) also mention that humor can be found in various forms such as puns, pantomimes, caricatures, sitcoms, music, and events that make people laugh. We cannot separate humor from the context. An understanding of the same background of experience or knowledge is required to guarantee the funniness of humor. Billig (2005) emphasizes that humorous remarks are not merely created but also comprehensible. Different ways of creating humor also drive different purposes and functions. By involving spoken or written humorous discourse in a particular context, it yields distinctive functions based on the context. Rohmadi (2010) opines that humor can be one of the ways to convey messages or criticisms implicitly and explicitly.

Specifically, this study examines the function of humorous discourse based on the context of speech event in Mind Your Language, a comedy series written by Vince Powell produced by London Weekend Television in 1977. This sitcom show talks about the English learning process by immigrants from various countries, such as Japan, Germany, Italy, Pakistan, India, France, Greek, Spain, and China, with different basic knowledge and cultures. In addition, these immigrants also come from different occupational backgrounds. Humor, which appears, utilizes those differences, different ideologies, and political views. For example, a learner from Pakistan and India is portrayed as two students with constant conflict. Such historical conflict, different political viewpoints, and religion boldly involved caused that sitcom to be phenomenal and controversial. The complexity of humor creation at that sitcom is interestingly examined, not only the way the humor is produced but also the functions.

Several specific previous studies dealing with the function of humor as a medium of communication were carried out by Rahmanadji (2007) and Goldman (2013), as well as several previous research articles written by Hay (2000); Utami (2018); Suaib, Rafli, and Muliatuti (2019); Martin, Rich, and Gayle (2014); and Kholidah, Widodo, and Saddhano (2020). For example, Goldman (2013) delivers how humor can function as a medium of social correction. He provides a kind of illustration of how humor can be an implicit weapon to recorrect people's general view or perception about something. For example, An Arabian comedian in America, Dean Obeidillah, his humorous performance was to reduce and eliminate Islamophobia after the tragedy of September 11, 2001. Goldman, in that context, depicts the function of humor as a medium of large-scale social correction, one of the social functions of humor. Broadly speaking, Hay (2000) classifies the function of humor into three main general functions; the function of solidarity, the function of power, and the function of psychology. Those three categories are also involved as a contextual analysis framework in the discussion section of this humor research to reveal how interlocutors' background differences create unique humorous discourse and perform its function of humor.

\section{METHOD}

Since this research deals with wordbased sources, this humor research adopts qualitative research. Sen (2012) characterizes qualitative research as heavy dependence on data such as interviews, observer notes, documents, and manuscripts. Another characterization is given by Moleong (2009, p. $6)$, who outlines qualitative research as a research approach that is closely related to examining phenomena experienced by research subjects such as behavior, perceptions, motivations, actions, etc., holistically described in the form of words and a particular context. The data collection process was carried out by abstracting the dialogue in Mind Your Language's comedy series, especially in the first five episodes. Based on the emergence of humor in those five episodes, Hay's framework identified the humor function, which divides the functions of humor into solidarity, power, and psychological expression. Therefore, to determine the data for this research, the researcher involved artificial laughter or recorded laugh as a marker to the humorous utterances. According to Balmores-Paulino (2018), everyone has a natural ability to create humor. It is just the intensity of its practice that personalizes a person to be humorous or not. Additionally, everyone has a different sense of humor as well. 


\section{DISCUSSION}

One of the three paradoxes of the humor proposed by Billig (2005) is that humor is social by bringing togetherness in a bond of enjoyment. In contrast, humor is anti-social and performed by excluding others by mockery. Goldman (2013) uses the term as a double-edged sword to analogize humor construction's positive and negative effects. Below is a further understanding of humor creation in the Mind Your Language sitcom series.

\section{THE FUNCTION OF SOLIDARITY}

In each speech event and different contexts, humor can produce different functions. To express solidarity through humor, Hay (2000) classifies some of his findings into the functions of flirting, sharing, showing similarities, and maintaining boundaries within the in-group (see also Puriand Baskara, 2019 and Trianda, 2015). Humorous discourse in Mind Your Language utilizes humor to tease and satire to express the function of solidarity.

\section{Humor to Tease}

One of the humor functions identified to express solidarity is to tease the interlocutors. The researcher found that function in speech events involving Ranjeet, one of Mr. Brown's students, and Miss Courtney, the head of the language center, characterized as a stiff, cynical, and emphatic person in the conversation below.

\section{(Example 1)}

Miss Courtney: You.

Ranjeet: Yes, please, Missy. Can I be assisting you in any way whatsoever?

Miss Courtney: At last, a breakthrough. Are you in Mr. Brown's class?

Ranjeet : No, I'm in corridor.

In example (1), the conversation took place in the corridor in front of the classroom between Miss Courtney and Ranjeet. On the previous occasion, Miss Courtney tried to speak to Jamila and Juan, who could not speak English. Miss Courtney then saw Ranjeet, who was walking towards them, and she asked Ranjeet if he was Mr. Brown's student or not by uttering, are you in Mr. Brown's class. Ranjeet, a student capable of communicating in English, responded by saying, no, I' $m$ in the corridor. Ranjeet's response is relevant to Miss Courtney's question, but conceptually, Ali's response is not relevant to Miss Courtney's question. That inappropriate response above triggers humor because Ranjeet deliberately deviated the response even though he completely understood the intention of the question. Ranjeet deliberately uttered that humorous utterance to tease his stiff and cynical headmaster as an effort to reduce the social distance between a student and a school principal. One of the social functions of humor quoted by Buxman (1998) is to lessen the hierarchy between individuals and decrease the social distance. That scale points to the relevance of relative statuses, such as Holmes (2013) highlights that the school principal is in higher status than the students.

\section{Humor to Quip}

To express solidarity, people can convey humor in a quipped manner in a specific context. Balmores-Paulino (2018) mentions that making jokes about other people's physical form or character is reasonable as long as it is in the context of joking. In line with the finding, that context is also found in a slice of conversation involving close social relationship participants. Satirical humor can strengthen solidarity, as was found in the speech events below.

\section{(Example 2)}

Mr. Brown: You can't get married unless you love each other.

Surrinder: It is his duty to be marrying me; otherwise, I am losing my face.

Giovanni: I think she's lost it already.

A conversation above took place in the corridor in front of the classroom between Mr. Brown, Giovanni, and Surrinder, Ranjeet's fiancee, who came to collect Ranjeet's promise to marry her. On the contrary, Ranjeet always avoided meeting and refused to marry his fiancee due to physical reasons. Ranjeet assumed that his fiancee was very big, like an elephant. Surrinder stuck by their tradition as two engaged people that it was a duty for Ranjeet to marry her even though she lost her face. Hearing that Surrinder's utterance, Giovanni standing beside them, responded by saying I think she's lost it already. That satirical 
utterance illustrates the concept of incongruity in humor theory. A contradictory as a part concept in incongruity theory is identified in what Giovanni said and what he should be said. That situation required other interlocutors to show their sympathy to Surrinder. However, Giovanni's utterance exemplifies the lack of sympathy by quipping Surrinder through his humorous utterance. Giovanni just expressed their friendship closeness by quipping Surrinder with a joking gesture. Humor functions as a social adhesive (BalmoresPaulino, 2018) and (Suaib, Rafli, dan Muliastuti, 2019).

\section{THE FUNCTION OF POWER}

Hay (2000) and Puri and Baskara (2019) identify the function of power can be expressed by producing humorous discourse to build conflict, control, defy boundaries, and humor to tease. Similar to Hay and Puri and Baskara, Trianda (2014), more specifically, also finds humor to criticize and respond to the social phenomena as an expression of the function of power. That kind of humorous discourse function is drawn in the following explanation.

\section{Humor to Foster Conflict}

Triggering conflict through humorous discourse can be constructed by producing a sarcastic utterance, insulting, and mocking the interlocutor. The following examples illustrate how humor is shaped to insult interlocutors.

\section{(Example 3)}

Mr. Brown: I am English, you are Chinese; he is Italian! She is French.

Ranjeet : He is barbarian.

Ali: And you are asking for a kick up your big Brown backside.

Mr. Brown: Pay attention, please.

\section{(Example 4)}

Mr. Brown: Repeat after me. You are English.

Ali: No, I'm not! I'm from Pakistan.

Mr. Brown: What am I?

Ali: You are confusing me.

Ranjeet: You are stupid poof.

Ali: Don't you call me poof.

Those two examples above occurred in the classroom between Mr. Brown, Ranjeet, and Ali. Mr. Brown was teaching about to be in English, and he then asked Ranjeet, a student from India, to give an example using to $b e$. When Ranjeet made a sentence by uttering he is barbarian, he, at the same time, pointed at Ali. The emergence of recorded laughter to that Ranjeet's utterance indicated that his utterance was marked as humorous utterances. That humor produced by insulting another one triggers conflict. Ranjeet also conducted another humorous discourse by insulting someone else in example (4). Ranjeet, who kept listening to the conversation between Ali and Mr. Brown, responded to Ali's utterance by saying, you are stupid poof. That utterance indirectly triggers the emergence of laughter by insulting other people. From that response, it could be seen how Ranjeet produced a contradiction in the concept of incongruity not to insult others. Humorous discourse function by insulting the other at the context above is also generated their socio-political conflict between India and Pakistani as historically elaborated by Hasan (2005) and Mir (2014), and Yaseen, Jathol, and Muzaffar (2016) in a political viewpoint. Regardless of that longlasting conflict, Ali frequently conflicted with Ranjeet in verbal abuse or physical harshness.

In addition to the insulting function, people can humor by mocking interlocuter (Puri and Baskara, 2019). Several examples below demonstrate how humor is constructed to mock other people. Slightly different from insulting, as previously described, even though both are demeaning other people, mocking tends to show an expression of dislike or making fun of others based on their physical appearance or ability, as identified in the following examples.

\section{(Example 5)}

Mr. Brown: Yes, thank you, Juan, and thank you for carrying it. Yes, thank you very much.

\section{Giovanni: You Spanish creeper.}

Juan: You Italian

In example (5), a conversation took place between Mr. Brown, Giovanni, and Juan in the classroom. They came into the class together, and Juan kindly helped Mr. Brown by carrying his teaching bag. Juan also gave a hand to Mr. Brown to take his thick jacket off. When Juan listened to Mr. Brown's gratitude, Juan was on his way to his seat without paying any attention to his steps, and accidentally he hit Giovanni, who was still standing next to his 
seat. Feeling annoyed by Juan, Giovanni then mocked Juan by uttering you Spanish creeper. That utterance was signaled as a humorous utterance by mocking another person. The mocked utterance is delivered because of Juan's physical appearance, a thin and towering person. Giovanni's utterance is uttered to trigger conflict by mocking another one. The purpose of humorous discourse to mock is to demonstrate the speaker's strength against the interlocutor.

Moreover, humor to trigger conflict can also be exploited by the quipped interlocutor to avoid direct mocking. This quip utterance indirectly mocks the interlocutor in the humorous function of power. This case is also contextually different from the identical purpose of humor produced in the humorous function of solidarity.

\section{(Example 6)}

Mr. Brown: You're supposed to be pretending it's a real pain.

Ranjeet: A thousand apologies again! I have a real terrible pain.

Mr. Brown: Good. Where is this pain?

Ranjeet: In my foot.

Ali: His brains are hurting.

Ranjeet: Your backside will be hurting in a moment.

Ali: Blimey you can't even crack a popadum.

Mr. Brown gave a practical lesson in speaking practice based on daily conversations in public places such as hospitals, post offices, and banks. Mr. Brown was supposed to be a doctor, and he asked Ranjeet to be a patient. Mr. Brown asked Ranjeet to repeat his utterance with a more apparent illness complaint. Ranjeet claimed that his leg was excruciating by lifting his right foot on the table. A verbal clash between Ali and Ranjeet occurred after Ranjeet complained of his illness to Mr. Brown. At the end of the dialogue, Ali mocked Ranjeet by quipping his physical ability by uttering, blimey you can't even crack a papadum. It means that Ranjeet is not strong enough to hurt Ali as Ranjeet intimidates. The utterance quipping interlocutor uttered by Ali aims to indirectly mock Ranjeet as a fragile guy who cannot hurt him. Ali and Ranjeet's clash reveals how incongruity is exploited to evoke laughter in the context above. A contradiction in incongruity theory of humor is found in Ali's utterance that Ranjeet will not be able to crack papadum, a flat and thin Indian food. However, every adult can crack papadum, or even children can effortlessly crack that Indian flimsy bread.

\section{Humor to Harm}

In a particular conversational context, humorous discourse is exploited to express an attitude of superiority by harming other people. The superiority in the Mind Your Language comedy series is occasionally demonstrated by producing humor to ignore and harm interlocutors. To harm others, people can articulate superiority through the linguistic expression which elicits humor. The humorous discourse to harm interlocutor can be seen in the example conversation below where Ali asserted his desire to ease Ranjeet to suicide.

\section{(Example 7)}

Mr. Brown: You mean you're going to die?

Ranjeet: Most definitely. I'm going to die by my own hand.

Ali $\backslash$ : If you are wanting some assistance. I am happy to be helping.

Mr. Brown: I thought you didn't like Sikhs.

Ali: That is why I am happy to be helping.

Ranjeet, who is facing a big problem, had an intention to end his life with his hand. He shared his problem with Mr. Brown and his friends in front of the class. Ali, who heard Ranjeet's plan to end his life, then opportunely offered to help Ranjeet kill him by saying, if you want some assistance, I am happy to be helping. The rise of the artificial laughter at that utterance specified it as a humorous utterance with a particular function of humor. As Kuipers (2009) emphasizes that incongruity is the central ingredient of humor construction, the concept of incongruity can be seen in Ali's utterance, which contented to kill his classmate, Ranjeet. Ali as Ranjeet's classmate, should help Ranjeet to solve his problem. Ali's response above shaped a contradiction that he precisely was delighted to end Ranjeet's life. That humorous utterance is employed to express the function of power to harm Ranjeet. In addition to eliciting humor by harming others, people can produce humorous discourse to ignore the interlocutor who needs help. The humorous discourse below demonstrates the co-worker's behavior, who 
frustrates his mate so that he ignores helping his mate.

\section{(Example 8)}

Policeman: Hello. Polisi Wilkins? Where the devil are you? You should've been back here by now. Pardon? No, I will not send a Panda car for you. I don't care if somebody has pinched your bicycle! Pinch somebody else's.

In example (8), the utterance occurred at the police station between a police officer, Wilkins, and his colleague who was on his way to the office. Wilkins' mate phoned him to ask for any assistance to pick his friend up because the bike he was riding had been stolen. Wilkins, who seemed to get mad because his colleague arrived late, refused to send a car for him. Furthermore, Wilkins precisely instructed his mate to pinch someone else's bike. Wilkins utilizes the concept of incongruity that he should help his colleague, and as a police officer, he should enforce the law. He should not suggest his mate steal a bicycle. Wilkins ignored to give his colleague a hand, and he also asked his colleague to pinch somebody else's bicycle. It indicated that Wilkins suggested his colleague do something against the law. That humorous discourse above contradicts what Wilkins commanded and what he should command. The ignorance of the interlocutor's need through the humorous discourse indicates that humor is constructed to express the humorous function of power.

\section{Humor to Threaten}

One of the typical functions of humor is humor to threaten (Wangsomchok, 2016). Humorous discourse to threaten is also found in Puri and Baskara (2019) to express power function in humor. In a specific context, threatening can be manipulated to evoke laughter as long as it contains incongruity and unexpectedness, as in the example below.

\section{(Example 9)}

Danielle: Oh Max, can you help me?

Max: Sure, anything you want

Danielle: I am in very big trouble.

Max: I kill him.

Danielle: Who you kill?

Max: The man who put you in big trouble.

Danielle: There's no man.
Max, who adored Danielle, paid serious intention to Danielle's recent uncomfortable experience. Danielle did not yet clear what problem she had, and Max suddenly responded to Danielle by uttering humorous utterances to threaten someone else. Danielle, who had not finished her assignment, told Max that she was in a big problem. Max suddenly uttered I kill him to Danielle without precisely knowing Danielle's problem. The unexpectedness of Max's response elicits humor because he suddenly threatened to kill the man from whom Danielle got the problem. There is one man who had a problem with Danielle. However, Max's utterance on the conversation portrayed an unexpected mismatch between Danielle's problem and Max's supposition to Danielle's problem. Max constructs that humorous utterance to express the function of power by threatening someone else.

\section{Humor to Blame}

People can demonstrate the humorous function of power by accusing or blaming others. Blaming someone else is categorized as one of the humor functions highlighted by Wangsomchok (2016). In the following example, the police officer indirectly blames Mr. Brown as an English teacher because one of his students stole a magazine from a bookstore.

\section{(Example 10)}

Mr. Brown: And she thought the whole book was free.

Policeman: Yes.

Mr. Brown: So it wasn't her fault.

Policeman: If anyone's to blame, it's the person who's teaching her English.

The conversation above took place at the police station between Mr. Brown and an officer. The police officer arrested Jamila, one of Mr. Brown's students who did not know English, because she was accused of being a shoplifter in a bookstore. She took the magazine from the bookstore without paying for it. It happened because a free supplement was written on its cover, and Jamila considered that the whole magazine was free. Mr. Brown ascribed that the case was a hundred percent just misunderstanding because Jamila thought the book was free and could take it without paying for it. Then the police responded by uttering if anyone's to blame, it's the person 
who's teaching her English which indicated that Mr. Brown should be responsible for Jamila's case. Indirect accusing something to someone who did not do that illustrates unexpectedness and contradiction in the concept of incongruity to evoke laughter. The one who acted against the law should take responsibility. That humorous discourse above is elicited to express the function of power by blaming another person.

\section{Humor to Express Disagreement}

Producing a humorous discourse function to refute can indicate that the speaker has the power to do so. Besides expressing an opposite viewpoint, that disagreement probably contains humor if the arguments to the subject disputed are irrelevant to one and another, as highlighted in the following example.

\section{(Example 11)}

Juan: In my country Spain, most of the people are Roman Catalyst.

Miss Courtney: I don't believe it.

Giovanni: That's not right.

Juan: No?

Giovanni: Italy is a much bigger catalyst country.

At that time, Miss Courtney took over Mr. Brown's class because he came late. Mr. Brown prepared several kinds of stuff as learning practice material. Miss Courtney asked Juan to make a sentence using the word Catalyst when handling the class. However, a sentence arranged by Juan did not appropriately use the word Catalyst. The sentence was in my country Spain, most of the people are Roman Catalyst. Juan incorrectly perceived the word catalyst as catholic. Giovanni, who could not accept the sentence, uttered that Italy is a much bigger catalyst country. The contradiction between what Miss Courtney asked and what Giovanni and Juan debated illustrates a mismatch concept in incongruity theory. Marmysz (2003) and Kuipers (2009) mention that difference, contrast, and mismatch elements are fundamental characteristics to elicit humor. Conveying the disagreement to another opinion can be manipulated to be funny by arguing unexpectedness and irrelevant response to the topic.

\section{THE FUNCTION OF PSYCHOLOGY}

According to Hay (2000), the third function of humor is a psychological function. This function is closely related to humor created to foster the psychological effects. Buxman (1998) underlines the psychological function of humor as a primary coping mechanism, such as releasing anxiety and tension, serving as an outlet for hostility and anger, and providing a healthy escape from terrible reality. Related to the previous studies, the humor in Mind Your Language situation comedy is created to the psychological function such as humorous discourse to gain the advantage, protect themselves, entertain, confuse the interlocutor, boast, and say taboo words, and disturb the interlocutor.

\section{Humor to Gain Advantage}

Humorous discourse utilized to gain selfadvantage purposes often involves humor beyond the utterance. Humor verbally uttered to gain an advantage is frequently conveyed to reduce the risk of embarrassment if the effort to gain an advantage is not achieved, as in examples 12 and 13 below. The conversation sample confirms how Ali and Max are trying to gain an advantage despite being against the norms.

\section{(Example 12)}

Mr. Brown: Pinching a magazine is one thing, but knocking off half a supermarket is rather a different matter. On the other hand, we can't let Jamila keep all these stolen goods! It's dishonest.

Ali: She can give them to me! I do not mind to be dishonest.

Mr. Brown: Yes, I'm sure you're not.

\section{(Example 13)}

Mr. Brown: What we need is something to be attracting the attention of passerby.

Max: Yes, Danielle should wave from window by herself.

Mr. Brown: It still may not be sufficient to attract enough attention.

Max: It would be if she took all her clothes off.

Giovanni: That's a good idea.

Mr. Brown: No, it isn't.

A conversation in example (12) took place in Jamila's apartment after Mr. Brown, and Ali picked up Jamila arrested as a shoplifter at the police station even though that accident, at last, was utterly a misunderstanding. A 
similar case happened again. Because her English was so poor, Jamila did not pay for all goods she took from a supermarket because of a lettering-free offer that Jamila perceived the stuff was free. Mr. Brown proposed that Jamila could not keep the items she stole, and he planned to bring them back to the supermarket. While Mr. Bown was considering his idea, Ali tried to gain an advantage by uttering she could give them to me! I don't mind to be dishonest. That utterance was marked as humorous utterance with the emergence of recorded laughter. It could be seen how Ali produced unexpectedness and contradiction to keep that stolen stuff, and he did not mind being dishonest. An unexpected utterance that elicited humor was also uttered by Max in example (13). Mr. Brown and his students were locked in the class on the third floor. Failed to break the door-class, they then waved their hands to attract the attention of passersby. Their efforts did not make sense because their class was on the third floor. Max suggested that Danielle, a female class participant from France, was able to attract the attention of passersby alone by waving without any clothes on her. Max unexpectedly produced a contradiction between what Danielle may do and what Danielle may not. As a student, it is not allowed to take all their clothes off, particularly during the lesson class.

\section{Humor to Protect}

The humorous discourse function to protect oneself designates the same idea with Trianda (2014) and Puri and Baskara (2019), who classified this function of humor to defend, creating a defense for the potential critics. Furthermore, this function is also employed to protect oneself from various possible verbal attacks, such as accusations or ridicule, as presented in the following example.

\section{(Example 14)}

Mr. Brown: I checked your homework last night. And I have a feeling there have been some sort of chicanery going on.

Giovanni: We not know what you mean.

Mr. Brown: Well, Giovani! I'll tell you. Firstly, there's the fact that five of them are written in the same hand.

Giovanni: It's a sheer coincidence.
Mr. Brown told his students that he had checked their assignments, and Mr. Brown felt he had discovered a sort of cheating. Besides explaining the same incorrect part of their assignments, Mr. Brown confirmed that each student's answer sheet was written in the same writing characteristics. Giovanni considered that their answer sheets written in the same handwriting were coincidental by uttering it's a sheer coincidence. Giovanni, who previously sold the answer sheets for the assignment to his friends, tried to divert Mr. Brown's suspicion. The difference between what Giovanni said and what happened demonstrates how he exploited the concept of incongruity to generate humor. That humorous discourse produced by Giovanni aims to protect himself because Mr. Brown realized that his students were cheating on their assignments. However, that circumstance psychologically pushed Giovanni to protect himself because he had lied to his teacher.

\section{Humor to Entertain}

Humorous discourse constructed to entertain is one of the primary purposes of humor creation in psychological function. This function is also identified in several previous kinds of research conducted by Asyura, Effendy, and Martono (2014), Hay (2000), and Utami (2018). Therefore, it is in line to produce a sitcom series to entertain the audience.

\section{(Example 15)}

Ali: I am coming to be learning the English.

Miss Courtney: You're early.

Ali: No, I am Ali.

Miss Courtney: I beg your pardon?

Ali: My name is Ali. Ali Nadim.

As a new student on the first day of the class, Ali Nadim came to Miss Courtney's room to ask which class he should be in. Miss Courtney told Ali that he came too early for the class by uttering, you're early. Ali perceived the pronunciation of early as his name's mispronunciation, so then he responded by uttering no, I am Ali. An ability to use a language, intentionally or unintentionally, will potentially lead the speaker to produce an irrelevant response as Ali did. From that context, it could be seen how Ali's response was not relevant by introducing his name. That mismatched utterance triggers the existence of 
humor through the contradiction and unexpected response. As stated by Kuipers (2009), humor is synonymous with incongruity. One of these deviations initiates a misperception, resulting in a response discrepancy. In the following example, a sample of producing irrelevant responses caused by the speech sound ambiguity or misperception was captured in Anna's utterance. When Mr. Brown asked a follow-up question about flour, Anna perceived flour as $a$ flower. Anna supposed the speech sound of flour as flower, two different English words with different concepts and meanings. Anna defined flour as a thing worn at the wedding. Both Ali and Anna produced irrelevant responses to elicit humor.

\section{(Example 16)}

Mr. Brown: It's flour! You know what flour is?

Anna: Ja, what you wear at wedding.

Mr. Brown: No, no, no, this isn't that kind of flower! This is flour to make pastry and bread.

Contextually, the humorous discourse created to entertain can also be expressed in several ways: saying taboo words, confusing and irritating the interlocutor. Confusing the interlocutors can be realized by using unfamiliar dialect or language practice. Using a particular language practice, cockney slang, for instance, is hard to be understood by English learners. Besides being motivated by different language habits usage, rhyming slang is infrequently used in daily conversation for second language learners.

\section{(Example 17)}

Giovanni: What we're gonna talk about?

Sid: You'll have to talk up. I'm a bit Mutt and Jeff. Max: Excuse me! Who are these Mutt and Jeff?

\section{(Example 18)}

\section{Sid: I don't mind! I'm just happy to rest my plates} of meat.

Ranjeet: Excuse please! I am not seeing any plates of meat.

Sid: Plates of meat is feet.

In examples (17) and (18), those two examples provide the humorous discourse construction by employing rhyming slang. Sid is a cockney that exactly experts in communicating by using rhyming slang. In contrast, rhyming slang was strange for his
English learner interlocutors. Even though Sid realized that they were English learners, Sid still spoke cockney slang they did not understand. The use of the rhyming slang you'll have to talk up. I am a bit Mutt, and Jeff was found in the example (17) and the slang I'm just happy to rest my plates of meat in example (18). Sid's different capability and his interlocutors' speaking rhyming slang confused his interlocutors.

Furthermore, as English learners, they never expected their interlocutor to speak English rhyming slang. Sid's utterances, those rhyming slang confusing Ranjeet, Max, and Giovanni, automatically provoke laughter. Those humorous utterances were characterized by unexpectedness in the incongruity theory of humor to confuse interlocutors. However, in regular communication, Sid could replace the rhyming slang with the common word deaf for Mutt and Jeff and feet for plates of meat to ease his interlocutors in understanding the utterance.

In addition to using a very particular word confusing interlocutors, the existence of taboo words potentially triggers humor. Lewis (2016) classifies taboo words as forbidden words. Wardhaugh (2006, p. 239) defines "Taboo as a prohibition or circumvention of the beliefs of certain community behaviors that will endanger members of the community group where it will make them feel anxious, embarrassed, and humiliated."

\section{(Example 19)}

Mr. Brown: Who was this lady who detained you in the corridor?

Ranjeet: Oh, blimey! I am forgetting her name. She was big lady-very large bosoms.

Juan: Grandioso, very good!

When Ranjeet intended to respond to Mr. Brown's question, he did not remember the name Mr. Brown asked. However, he remembered the person's characteristics by saying she was the big lady-very large bosoms. Choosing to mention one of the woman's vital body parts in this context, Ranjeet described the woman to give a clue to Mr. Brown. Even though Wardhaugh (2006) classifies human body parts, especially vital organs, as taboo expressions, mentioning that 
part in joking circumstances lessen the notion of the taboo words as forbidden words. It also depends on the participants of the speech event. As Ranjeet demonstrated in example (19), he did not remember yet the name he had to mention, so he described that person by uttering very large bosoms. The expression of That taboo word by force to be mentioned potentially evoke laughter instead. That humorous utterance confirms that taboo words, in a particular context, can be manipulated to construct humor.

\section{(Example 20)}

Mr. Brown: I want you to give me a sentence using 'you are.'

Ali: I am.

Mr. Brown: No, not 'I am,' 'you are! For example, you are from Pakistan.

Ali: I am from Pakistan.

Mr. Brown: Yes, but now use 'you are.'

Ali: But I cannot say you are from Pakistan because you are not, are you?

Mr. Brown: Repeat after me. You are English.

Ali: No, I'm not! I'm from Pakistan.

Mr. Brown: What am I?

Another way to create humorous discourse to entertain is by producing utterance that irritates the interlocutor. In contrast to the function to express solidarity, irritating interlocutor to express psychological function tends to have a psychological impact as Ali did to Mr. Brown in the example above, how Ali made Mr. Brown mad. Mr. Brown, who was teaching his students about the use of to be in English, asked Ali to make a sentence using you are. Instead, Ali repeatedly used I am to make a sentence even when Mr. Brown provided various examples. Based on the conversation above, not only inappropriate response given by Ali, Mr. Brown was furious because of the frequent incorrect response given. The difference between what sentence Mr. Brown expected and what sentence Ali made captured the contradiction in constructing humorous utterance. Furthermore, Mr. Brown did not expect Ali to repeatedly ignore his correction, who spoke English fluently.

\section{Humor to Boast}

Being boastful commonly offers an awkward segment in communication, leading the interlocutors to typically not respect the speaker. Thus, it happens if that attitude is found in humorous exchange by showing the opposite fact of the claim as served by Miss Courtney in the following example.

\section{(Example 21)}

Miss Courtney: My apologies Mr. Kenyon. I do assure you that Mr. Brown will be severely dealt with.

M. Kenyon: I can't remember when I last enjoyed myself so much.

Miss Courtney: I beg your pardon?

Mr. Brown: Enjoy yourself?

Mr. Kenyon: You know Miss Courtney, your Mr. Brown is a remarkable man.

Mr. Brown: I am?

Miss Courtney: He is?

Mr. Kenyon: Yes! His teaching methods may be revolutionary, but they appear to work.

Miss Courtney: I've always encouraged my staff to be forward-thinking.

Mr. Kenyon, as a supervisor of the local education authority, was monitoring the school. At the end of supervising, he complimented Mr. Brown's teaching method in his class in front of Miss Courtney. Miss Courtney, at that time, asserted that she always encouraged her staff to be forward-thinking. That implicated that she played an essential role in what her staff was achieved in any teaching models. Miss Courtney never did that. The funniness came from the contradiction between Miss Courtney's claim and that she did not do. That humorous discourse was created to boast that her staff's excellence was because of her encouragement as a psychological expression from a headmaster that needed to personalize herself as a credible and outstanding leader.

\section{CONCLUSION}

The humorous discourse function originated at the one context of speech event is potentially different from another function in numerous contexts. The context of speech events is very influential and cannot be separated in identifying the functions of the humorous discourse. Mind Your Language situation comedy employs various humorous functions. First, humorous discourse is created to tease and quip interlocutors to express solidarity. Fostering conflict, harming, threatening others, and disagreement through 
humorous discourse construction are initiated to express the humorous function of power. Besides those two functions of humor, psychology functions in articulated by constructing humorous discourse to gain the advantage, protect oneself, entertain, and boast. From a general viewpoint, the function of humorous discourse can be classified based on social function and psychological function. The social function represents the solidarity function and the power function, while the psychological function focuses on the psychological aspects of the participants. The ways of uttering humorous discourse are probable to indicate the exact purpose of humor construction. However, they can still be distinguished into one of the three main functions of humor where the background or the context of the humor creation process is in a crucial role.

\section{REFERENCES}

Asyura, M., Effendy, C., and Martono. (2014). Makna dan fungsi humor dalam kumpulan cerita Abu Nawas. Jurnal Pendidikan dan Pembelajaran Khatulistiwa 3(4), 1-15.

Balmores-Paulino, R. S. (2018). An exploration of the schema and function of humor. Israeli Journal for Humor Research 7(2), 43-63.

Billing, M. (2005). Laughter and ridicule: Towards a social critique humor. London: SAGE Publications.

Buxman, K. (1998). Humor as a cost-effective means of stress management. Managing Employee Benefits 6(2), 74-78.

Goldman, N. (2013). Comedy and democracy: The role of humor in social justice. Animating Democracy, 1-10.

Hasan, S. (2005). India and Pakistan: Common identity and conflict. Refugee Survey Quarterly 24(4), 74-80.

Hay, J. (2000). Functions of humor in the conversations of men and women. Journal of Pragmatics 32, 709-742.

Holmes, J. (2013). An introduction to sociolinguistics. London: Routledge.

Hurley, M. M., Dennett, D. C., and Adams Jr., R. B. (2011). Inside jokes: Using humor to reverse-engineer the mind. Massachusetts: MIT Press.

Kholidah, N. N., Widodo, S. T., dan Saddhano, K. (2020). Traditional stage as a medium of social criticism: The role of humor in ludruk performance art. Journal of Critical Reviews 7 (7), 1-5.

Kuipers, G. (2009). Humor styles and symbolic boundaries. Journal of Literary Theory 3(2), 219-240.

Lewis, J. P. (2016). “Forbidden words." Torch magazine, p. 2-6.

Malphurs, R. A. (2010). People did sometimes stick things in my underwear: The function of laughter at the U. S. supreme court. Communication Law Review 10(2), 48-75.

Marmysz, J. (2003). Laughing at nothing. New York: State University of New York. 
Martin, D. M., Rich, C., and Gayle, B. M. (2004). Humor works: Communication style and humor functions in manager/subordinate relationships. Southern Communication Journal 69(3), 206222.

Meyer, J. C. (2000). Humor as a double-edged sword: Four functions of humor in communication. Communication Theory, 10(3), 310-331.

Mir, M. A. 2014. India-Pakistan: The history of unsolved conflicts. IOSR Journal of Humanities and Social Science 19(4), 101-110.

Puri, A. D. dan Baskara, F. X. R. (2019). The function of humor applied in Margaret Cho's stand-up comedy: PsyCHO. Journal of Language and Literature 19(1), 137-144.

Rahmanadji, D. (2007). Sejarah, teori, jenis, dan fungsi humor. BAHASA DAN SENI, 35(2), 213-221.

Rohmadi, M. (2010). "Strategi penciptaan humor dengan pemanfaatan aspek-aspek kebahasaan". Humaniora 22, 285-298.

Ross, A. (2005). The language of humor. New York: Routledge Taylor and Francis e-Library.

Sen, A. (2012). Humor analysis and qualitative research. Social Research Update, 63, 1-4.

Suaib, E., Rafli, Z., dan Muliatuti, L. (2019). Tipe dan fungsi humor dalam acara Indonesia Lawak Klub di Trans 7. Madah: Jurnal Bahasa dan Sastra 10(1), 123-136.

Trianda, A. (2014). "Analisis wacana humor verbal dalam film kill the messanger", Tesis Program Pascasarjana Ilmu Linguistik, Fakultas Ilmu Budaya, Universitas Gadjah Mada.

Utami, I. I. (2018). Strategi humor pada acara stand-up comedy. Adabiyyāt: Jurnal Bahasa dan Sastra $2(2), 219-245$.

Wangsomchok, C. (2016). A linguistic strategy to express humor in Thai. International Journal of Social Science and Humanity 6(6), 462-465.

Wardhaugh, R. (2006). An introduction to sociolinguistics. Oxford: Blackwell.

Yaseen, Z., Jathol, I., and Muzaffar, M. (2016). Pakistan and India relations: A political analysis of conflicts and regional security in South Asia. Global Political Review 1(1), 1-9. 